\title{
DARDER, ANTONIA (2016). Freire e educação. Ramada: Edições Pedago
}

A obra, "Freire e Educação" (Tradução do original publicado pela Routledge, em 2015, Freire and Education) está recheada de sentimentos, emoções e reflexões críticas, de luta e resistência contra as formas de opressão sobre as classes trabalhadores e "comunidades de cor" colonizadas nos Estados Unidos da América (EUA), e que a autora identifica como formas de repressão contra o desenvolvimento de uma educação humanista. Não sendo uma obra autobiográfica como a própria autora, Antonia Darder, refere no prefácio (p.12), assenta nas suas histórias de vida experienciadas, na reflexão crítica, na investigação e permanente resistência ao imposto pelas políticas hegemónicas do neoliberalismo, e fá-lo sempre em interação com os outros que fazem parte da sua humanidade e com os conhecimentos que Paulo Freire deixara gravados em texto.

A autora é professora na Loyola Marymont University nos EUA, e enquanto investigadora reconhecida internacionalmente, deixa bem claro nesta obra as suas motivações de investigação, ou seja, a luta contra os problemas que afetam uma educação que a todos respeite e que com todos contribua para edificar o seu projeto humano. Tal como concetualiza as problemáticas da educação em "Freire e Educação", também como já se referiu, o seu projeto de reflexão crítica e emancipatória teve como alicerce as suas experiências de vida, que conduziram ao estudo de doutoramento Critical Pedagogy, Cultural Democracy, and Biculturalism: The Foundation for a Critical Theory of Bicultural Education, o que logo permite compreender a mensagem na capa da obra que aqui se analisa - "O que é essencial é que os que aprendem... mantenham viva a chama da resistência que aguça a sua curiosidade e estimula a sua capacidade de arriscar".

Ao longo dos 4 capítulos que compõem a obra, e no contínuo diálogo que estabelece com o pensamento de Freire, Antonia Darder revela teorizações construídas sobre ideias/conceitos-chave das obras do filósofo da educação mais influente ao longo dos tempos, tais como Pedagogia do Oprimido, Pedagogia da Libertação, Pedagogia do Amor, Conscientização e Diversidade, entre outros. A intenção da autora é tornar clara a forma como os textos de Freire, assentes na dialética entre a filosofia e a pedagogia crítica, foram por ela capturados e a influenciaram na sua vida académica e na sua 
ação política, "na força de anunciar justiça", para as comunidades espoliadas das condições fundamentais para o ser Pessoa. Toma como referência a Pedagogia do Oprimido, para narrar e analisar factos históricos provocados pelo colonialismo, caracterizados por formas de sofrimento e de opressão das dimensões da existência humana, colonialismo vivido pela própria autora. É nesta contextualização que convoca a visão humanista e política de Paulo Freire, para fundamentar as exigências dos movimentos de educadores e ativistas de "cor", em que a luta se centra na mudança dos processos de vida nas escolas e nas estruturas sociais das comunidades colonizadas, tendo em vista a criação de condições para uma escola mais democrática, onde seja possível aceder a formas emancipatórias de aprender.

É de realçar o facto de, nesta obra, a autora designar o professor de EDUCADOR, conceito mais completo para designar alguém que tem à sua responsabilidade alunos em formação, na construção do conhecimento sobre si, sobre os outros e sobre o mundo, para quem a mera função instrutória, prescrita num curriculum pré determinado e igual para todos, ou como designou Formosinho (2007) "currículo uniforme pronto-a-vestir de tamanho único", não apresenta condições para uma educação libertadora e emancipatória, potenciadora da construção da humanidade de cada aluno diálogo com a Pedagogia da Libertação.

Este é um problema endémico das sociedades contemporâneas, que como sabemos, ultrapassa as fronteiras dos EUA, proliferando em muitos continentes e países, com o mesmo vigor, num enquadramento epistemológico pertencente à classe dominante, forçando educadores e alunos à submissão intelectual das ideologias e conhecimentos legitimados pelos Estados, em que o sucesso é visto como aquisição de conhecimentos, sistematicamente mensuráveis pela tutela, para perpetuar valores culturais e económicos que servem os intentos dos próprios Estados.

Tal como Antonia Darder refere, é urgente uma praxis crítica como forma de luta contra a força opressiva da escolarização, que liberte os educadores do autoritarismo e dos currículos estandardizados. Trata-se de criar condições para o sucesso de cada aluno, ou, usando a expressão da autora, que permita uma educação humanizante de forma diferenciada, no respeito pelos seus direitos e arriscando nas condições democráticas da escola, assentes na pedagogia do amor, implicando coragem do educador para correr riscos, ao subverter prescrições pedagógicas e curriculares. 
Antonia Dader considera que esta é a prática do amor revolucionário na sala de aula, tal como interpreta na fala de Freire, caminho que aponta como o possível para uma maior humanização da educação, salientando que algumas comunidades, "estão marcadas indelevelmente por séculos de genocídio, escravidão, colonização e exploração económica" (p. 71). Esta é a força das palavras da autora, que nos transporta para concetualizar a educação como um processo de reflexão crítica, de diálogo e de ação necessários à tomada de consciência dos alunos para a construção do conhecimento emancipatório, como uma prática revolucionária de resistência às estruturas de domínio. Isto é, pensar a ação de educar como um processo capaz de dar voz aos que são silenciados, de os incluir na participação da vida democrática da escola, pois é legítima a autoridade das suas histórias de vida, em vez de uma escola que molda a vida das pessoas, circunstâncias muito presentes no contexto dos EUA a que a autora se refere.

Ao longo do livro é constante o apelo à prática da pedagogia assente numa praxis crítica sistemática, como condição sine qua non à libertação das "comunidades de cor", num discurso ancorado em conceitos presentes nos escritos de Freire, entre eles, o conceito de inacabamento, ideia de humanidade inacabada. Porque não há saberes estanques que respondam à mudança e diversidade sociais, podemos considerar que ser educador assenta no princípio do "saber incompleto", tal como defende Sá-Chaves (2012) ao enfatizar a necessidade de abertura dos educadores à construção e reconstrução do conhecimento, sensibilidade, envolvimento e respeito pelas formas de ser e de aprender de cada sujeito Esta visão de inacabamento deve constituir um desafio para renovar e reinventar as escolas e as comunidades. Tal como a Antonia Darder refere, "a tarefa dos educadores críticos dedicados a um mundo mais justo... é adotar a ideia de que juntos, podemos transformar o nosso ensino e aprendizagem numa praxis revolucionária - uma praxis crítica que englobe a reflexão, o diálogo e a ação, onde a teoria e a prática se regeneram" (p. 54).

Vemos pois que toda a educação é política e politizada. É nas escolas que se pode criar espaços de liberdade e solidariedade, para fortalecer o direito de existir em sintonia com as histórias de vida daqueles que a frequentam. É uma exigência de democracia que requer coragem e persistência dos educadores, num envolvimento comprometido, em que a reflexão pessoal e coletiva é orientada para a formação de uma consciência 
sobre as consequências do pensamento e ação na praxis. Esta é a forma de praticar a pedagogia do amor que Antonia Darder interpreta de Freire, amor que respeita a diferença e transforma as condições sociais de desigualdade e desfiliação dos alunos, como práticas pedagógicas de resistência e contrahegemónicas. Ou seja, a pedagogia do amor está envolta em valores políticos que alimentam relações emancipatórias, integrando a esperança e a dignidade nas relações com os outros.

Solidariedade e diferença, libertação, pedagogia do amor e respeito pelos outros, educação humanizante e praxis crítica do corpo, entre outros, são conceitos-chave que atravessam toda a reflexão da autora nesta obra. $E$ porque emerge aqui uma conceção com contornos e reflexões pouco usuais, talvez seja de nos deter um pouco no conceito - praxis crítica do corpo. 0 conceito não é novo nos escritos que lemos sobre a pedagogia; contudo, apresenta-se com uma nova roupagem, ou um uso terminológico mais incisivo. Ler a obra permite uma apropriação mais cabal deste conceito. No entanto, e num esforço interpretativo das palavras escritas, poder-se-á considerar que o corpo assume um papel de relevo no contexto escolar, quando muitas vezes as suas formas de expressão física são silenciadas e reprimidas, vistas como condutas inadequadas em sala de aula, em vez de abordagens criativas e humanizantes, baseadas nas necessidades reais dos alunos e formas de expressão das suas culturas.

Diálogo e conscientização são, por assim dizer, conceitos-chave e transversais a toda a obra. O diálogo é entendido como indispensável para conhecer o mundo, logo é inerente ao processo de conscientização. Como é bem claro em toda a escrita da autora, educar em democracia é um projeto humano, que deve ser sistematicamente reinventado, através da vigilância atenta dos educadores, dos alunos e das famílias, implicando a sua participação e envolvimento na transformação das condições históricas e materiais que têm impacto nas suas vidas. É aqui que se forma uma consciência social e política responsável, que emerge e se desenvolve através da participação cívica e intencional. Esta é uma estratégia fulcral para a resistência às formas de opressão que a escola pode assumir, numa orientação de participação dos seus atores e autores na construção de formas de vida mais humanizantes e consequentes na luta contra as várias formas de reificação da pessoa.

A atitude prescrutora e inquietante de Antonia Darder está bem patente em toda a obra, mas chama-se a atenção do leitor para a parte final, em que 
o diálogo sobre vários problemas, com Freire e outros, é apresentado em discurso direto. Problemas como Marginalização, Poder e Conhecimento, Hegemonia em Contextos Progressistas, Saber o que Acontece na Sociedade, Contradição Opressor-Oprimido, entre outros, são de uma tal intensidade de pensamentos partilhados, que tornam credível o pressuposto de que a consciência sobre o mundo e a pedagogia é construída em diálogo coletivo, como princípio prático do desenvolvimento da democracia.

Porém, esta visão analítica sobre a educação que a autora nos apresenta fica demasiado restrita a fenómenos culturais, sociais e políticos dos EUA, não abrindo a reflexão a outros contextos e sociedades, onde proliferam fenómenos que, do mesmo modo, apresentam constrangimentos à edificação de uma educação humanista. Veja-se, por exemplo, fenómenos dos últimos anos, de povos de vários pontos do globo que, na busca de condições básicas de sobrevivência, na maioria das vezes, nem oportunidades têm para lutar pela educação das crianças, por tudo ou quase tudo Ihe ser negado, enquanto pessoas com direto à sua humanidade. E, apesar de a autora não considerar esta obra uma autobiografia, identifica-se alguma dificuldade de distanciamento emocional da sua própria história de vida, o que leva a enfatizar, com sistematicidade, propostas pedagógicas como forma de força contra-hegemónica do poder instituído que, em certa medida, cai em alguma redundância ao longo dos capítulos.

Termino, enfatizando a ideia de que esta obra é naturalmente de política educativa. Ela constitui uma forma de luta contra as sociedades dominadoras das comunidades trabalhadoras e de "cor" colonizadas e oprimidas, trazendo luz sobre possibilidades de encontrar caminhos de libertação, para uma educação humanista que restitua o direito a qualquer pessoa de construir a sua humanidade.

\section{Referências}

Formosinho, J. (2007). O currículo uniforme pronto-a-vestir de tamanho único. Mangualde: Edições Pedago.

Sá-Chaves, I. (2012). Supervisão. Indagatio Didactica, 4(2), 4-39.

Deolinda Ribeiro

Escola Superior de Educação, Instituto Politécnico do Porto, Portugal 